\title{
Competitive Usability Evaluation of Electronic Health Records: Preliminary Results of a Case Study
}

\author{
Romaric MARCILLY ${ }^{\mathrm{a}, \mathrm{b}, 1}$, Jessica SCHIRO ${ }^{\mathrm{a}, \mathrm{b}}$, Louise HEYNDELS ${ }^{\mathrm{a}, \mathrm{b}}$, Sandra \\ GUERLINGER $^{\mathrm{b}, \mathrm{c}}$, Annick PIGOT ${ }^{\mathrm{d}}$, and Sylvia PELAYO ${ }^{\mathrm{a}, \mathrm{b}}$ \\ ${ }^{a}$ Univ. Lille, CHU Lille, ULR 2694 - METRICS : Évaluation des technologies de santé \\ et des pratiques médicales, F-59000 Lille, France \\ ${ }^{b}$ Inserm, CIC-IT 1403, F-59000 Lille, France \\ ${ }^{c}$ CHU de Lille, Direction des Ressources Numériques \\ ${ }^{d}$ Lille Catholic Hospitals, Information department, F-59160 Lille, France
}

\begin{abstract}
It is necessary for hospitals to be able to compare the usability of electronic health records (EHR) before acquisition. Adding usability as a critical element of the procurement process is therefore crucial. During the competitive usability evaluation of several EHRs, the usability walkthrough method has the potential of making end-users more active in the procurement process than demonstrations. This case study presents first results of a comparison of three EHRs performed by nine representative end-users. All users uncovered usability problems while performing their scenarios. The results show that none of the EHRs evaluated is without major usability problems. These problems have been well-known to human factors researchers for a long time.
\end{abstract}

Keywords. Electronic health record, usability walkthrough, evaluation, usability, procurement process, user involvement

\section{Introduction}

To secure healthcare processes, hospitals are installing electronic health records (EHR). However, selecting an EHR is a critical decision with important consequences [1,2]. The presence of human factors issues may not only mitigate the expected positive impact of the EHR, but also alter work processes, hinder the activity of care professionals, and ultimately introduce new errors. Many studies have shown that failure to meet users' needs or the presence of usability problems can contribute to slowing technology adoption [3,4], clinician dissatisfaction [5], physician burnout [6] and may create patient safety issues [7-9]. When purchasing an EHR, hospitals should be informed of existing EHRs' usability. In the US, certifications requirements exist that compels vendors to publish an attestation that their EHR design has followed a user-center design process and their usability test results. However, the freedom left in the requirements application prevents to compare EHRs usability [10]. The procurement process is an opportunity for the purchaser to compare the usability of candidate EHRs by (i) introducing usability

${ }^{1}$ Corresponding author, Romaric Marcilly, romaric.marcilly@univ-lille.fr, Univ. Lille, CHU Lille, F59000 Lille, France. 
requirements in the request for proposal, (ii) conducting a competitive evaluation of the candidate EHRs' usability to select a short-list, and (iii) performing an in-depth usability evaluation of the remaining EHRs to make an informed purchase decision [11].

Competitive evaluation is the main step to compare several EHRs. However, in this step, users are often called upon only to attend EHRs' demonstrations by vendors. Even if methods have been developed to estimate usability during demonstrations (e.g., usability questionnaire for demonstrations in procurement, DPUQ [12], heuristic evaluation during the demonstration, HED [13]) and have proved to be useful, during demonstrations, attendees do not interact with the EHRs. Their perception of the usability could be impacted by the talent of the salesmen and above all, by a parametrization presenting the EHR favorably. Conducting formal user tests would allow users to interact with the technology and not be influenced by salesmen. However, it would not be costeffective at this stage of the procurement process to evaluate multiple EHRs in this way [11]. Schumacher et al. [11] proposed an approach that allows users to be active during the competitive evaluations without sacrificing cost-effectiveness: the usability walkthrough. During a usability walkthrough, representatives of each user group are asked to actually use the EHRs to perform typical tasks and to identify usability issues of the EHRs. The advantage of this approach is that the EHRs' usability can be compared by the users, thus limiting the influence of salesmen, under standardized conditions with the same scenarios and criteria. This case study illustrates the application of a usability walkthrough approach for the competitive evaluation of EHRs.

\section{Study context}

A private non-profit hospital in the north of France organized a procurement process to select its EHR (computerized provider order entry, medication administration record, and administrative data management system) to replace the solution whose contract was coming to an end. The request for proposal specified that applicants should make their EHRs available for a usability comparison by end-users. We took this opportunity to organize a usability walkthrough for comparing the usability of the applicant EHRs.

\section{Method}

Users' profiles most concerned with the EHR were selected by the procurement process team. Simultaneously, users members of the team, with the help of ergonomists, designed a set of realistic use scenarios and clinical data to allow going through the frequently used and critical EHR functionalities (Table 1). These scenarios were sent to vendors prior to the evaluation session so that the EHRs could be populated with relevant data.

Participants were given a group explanation of the usability walkthrough method (procedure, usability heuristics [14] and severity rating) two weeks before the evaluation sessions and just before the first session. Five evaluation sessions were organized, one per applying vendor, for a duration of three hours each (durations must be the same in the procurement process).

Each workshop began with a 30-minute explanation of how the EHR works by the vendor. Then, physicians and nurses were grouped in 3 pairs: to reproduce the intertwining of their tasks, each pair had to carry out its scenarios alternately on the same computer station. The pharmacist, the admissions officer, and the secretary performed 
their scenarios independently. Participants were asked to interact with the EHR following the scenarios while describing the usability problems they face along with their consequences and severity. An ergonomist supervised each group to record all comments and problems not seen by the participants. If participants had not completed the scenarios within two hours, they were asked to stop. Then a $1 / 2$ hour-debriefing session started with the completion of the system usability scale (SUS) [15] and continued with discussions about strengths and weaknesses of the EHRs. Vendors were not allowed to intervene during the evaluation.

Usability problems detected by the participants were completed by those identified by the ergonomist. They were sorted inductively by type and by severity.

Table 1. End-users' profiles and summary of the use scenarios to perform.

\begin{tabular}{ll}
\hline Profile & Summary of test scenarios \\
\hline $\begin{array}{l}\text { Pharmacist }(\mathrm{n}=1) \\
\text { Admissions } \\
\text { officer }(\mathrm{n}=1)\end{array}$ & $\begin{array}{l}\text { Validation of a prescription, entry of drug dispensation } \\
\text { Entry of new patient's administrative data, of administrative discharge, of } \\
\text { Secretary }(\mathrm{n}=1)\end{array}$ \\
$\begin{array}{l}\text { consultation and day hospital pre-admissions } \\
\text { Dictation transcription, search and entry of appointments bookings for consultation } \\
\text { and hospitalization }\end{array}$ \\
$\begin{array}{l}\text { Patient's arrival in the emergency room: entry of reason for admission, parameters, } \\
\text { prioritization, drug administration, patient orientation, transfer to another unit; }\end{array}$ \\
$\begin{array}{l}\text { Patient hospitalization: entry of the bed installation, of the syntheses, of the autonomy } \\
\text { and Braden scores, of the blood test, of the care plan, of the administration, of the } \\
\text { care delivery, of a traceability, of a catheter insertion, of the unit discharge, } \\
\text { visualization of the care plan, correction of an error, update of a targeted transmission } \\
\text { Patient's arrival in the emergency room: entry of observations, prescription, decision, }\end{array}$ \\
$\begin{array}{l}\text { and coding; Patient hospitalization: entry of history, of the home treatment, of } \\
\text { allergies, of the prescription, of the progress note, of the discharge order and coding, } \\
\text { visualization of lab results, of the care plan, of the prescriptions, of the observations } \\
\text { and of parameters, change in order, request for advice, dictation of discharge letter. }\end{array}$ \\
\hline
\end{tabular}

\section{Results}

Two vendors cancelled their application: one explained that its solution usability was not good enough, the other gave no reason. Not all scenarios were completed by the admissions officer, nurses, and physicians: only data obtained for the scenarios performed for the three EHRs were compared (Table 2). Due to length limitation, only the comparison of the types of the most severe problems is presented.

\section{Discussion and conclusion}

All users identified usability issues. None of the EHRs were usability problem-free, which impacted the quality of the interaction and participants' satisfaction. Two EHRs (A and B) received a low mean SUS score, describing their perceived usability as "poor" [16]. The third EHR stands out from the other two because fewer major problems were detected. During the test it also had a smoother interaction than the other two. This is reflected in a higher perceived usability score ("good"). During the debriefing, participants clearly expressed a preference for this EHR.

The problems detected mainly concern the adequacy between the work model integrated in the EHR and the actual work of the users. This is manifested by inadequate procedures, disrespect of task allocation, and by missing or insufficiently visible 
information and features which prevent users from using the EHR in the most efficient way. Other problems concern the effective presentation of information (labels and icons), error management and workload (long lists, complex procedures). The problems encountered correspond to problems well-known in the literature, some of which have been known for nearly 20 years and for which guidelines have been established [17].

Table 2. Major usability issues sorted by type, by EHR, and by professional who uncovered it (Physician,

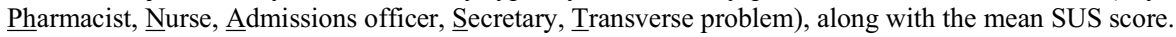

\begin{tabular}{|c|c|c|c|}
\hline Types of issues & A (SUS = 51) & $\begin{array}{l}\text { EHR } \\
\text { B }(\text { SUS }=45)\end{array}$ & C (SUS = 73) \\
\hline $\begin{array}{l}\text { Mismatch } \\
\text { between } \\
\text { practice and } \\
\text { system demand }\end{array}$ & $\begin{array}{l}\text { Chronic pathologies date } \\
\text { entry is mandatory }(\mathrm{P})\end{array}$ & $\begin{array}{l}\text { Insurance number required at } \\
\text { the emergency entry (A); } \\
\text { Appointment scheduling } \\
\text { procedure not intuitive (S) }\end{array}$ & 1 \\
\hline $\begin{array}{l}\text { Lack } \\
\text { feedback }\end{array}$ & $\begin{array}{l}\text { No feedback after ordering } \\
\text { change }(P)\end{array}$ & Lack of feedback (T) & / \\
\hline $\begin{array}{l}\text { Confusing } \\
\text { labels and icons }\end{array}$ & $\begin{array}{l}\text { Arrow icon taken for going } \\
\text { backwards while allowing } \\
\text { to change patient }(\mathrm{S})\end{array}$ & $\begin{array}{l}\text { Unclear drug frequency }(\mathrm{P}) \text {; } \\
\text { Same items with different } \\
\text { impacts on the care plan }(\mathrm{P}) \text {; } \\
\text { Drug information not } \\
\text { understood }(\mathrm{Ph})\end{array}$ & $\begin{array}{l}\text { Confusing } \\
\text { "save/validate" } \\
\text { buttons }(\mathrm{P})\end{array}$ \\
\hline $\begin{array}{l}\text { Legibility } \\
\text { issues }\end{array}$ & $\begin{array}{l}\text { Poor legibility of drug } \\
\text { timing: "D/O" confused }(\mathrm{P})\end{array}$ & का- (- & / \\
\hline High workload & $\begin{array}{l}\text { Long list of irrelevant items } \\
\text { (P); Complex history entry } \\
(\mathrm{P}) \text {; lack of overview of } \\
\text { patient record }(\mathrm{P}) \text {; Difficult } \\
\text { access to entry fields (T); } \\
\text { Complex drug by drug } \\
\text { validation }(\mathrm{Ph})\end{array}$ & $\begin{array}{l}\text { Contra intuitive checkmark of } \\
\text { the boxes }(\mathrm{Ph})\end{array}$ & $\begin{array}{l}\text { Long lists of items } \\
(\mathrm{T}) ; \quad \text { Erroneous } \\
\text { orders must be } \\
\text { stopped and re- } \\
\text { written }(\mathrm{T})\end{array}$ \\
\hline $\begin{array}{l}\text { Information: } \\
\text { missing }\end{array}$ & $\begin{array}{l}\text { No drug nor history in the } \\
\text { synthesis }(\mathrm{N}) ; \quad \text { No } \\
\text { obstetrical history items (P) }\end{array}$ & $\begin{array}{l}\text { No size unit }(\mathrm{N}) \text {; Missing drug } \\
\text { frequencies }(\mathrm{P}) \text {; Not detailed } \\
\text { contraindications }(\mathrm{Ph})\end{array}$ & $\begin{array}{l}\text { No timestamping of } \\
\text { the samples taking } \\
\text { (N) }\end{array}$ \\
\hline $\begin{array}{l}\text { Information: } \\
\text { lost }\end{array}$ & / & $\begin{array}{l}\text { Entered orders or notes not } \\
\text { found }(\mathrm{P})\end{array}$ & $\begin{array}{l}\text { Entered data not } \\
\text { found (treatments, } \\
\text { history, ICD-10) (P) }\end{array}$ \\
\hline $\begin{array}{l}\text { Information: } \\
\text { not visible } \\
\text { enough }\end{array}$ & $\begin{array}{l}\text { Patient ID not noticed }(\mathrm{P}) \text {; } \\
\text { Prescription changes in too } \\
\text { small font }(\mathrm{Ph})\end{array}$ & $\begin{array}{l}\text { Patient ID not visible on the } \\
\text { screen (S); Dosage information } \\
\text { not visible }(\mathrm{P})\end{array}$ & / \\
\hline $\begin{array}{l}\text { Features: } \\
\text { missing }\end{array}$ & / & $\begin{array}{l}\text { Non-customizable drug dosage } \\
\text { cycle }(\mathrm{P}) \text {; Impossible to enter } \\
\text { pharmaceutical intervention or } \\
\text { to substitute non-formulary } \\
\text { drugs }(\mathrm{Ph})\end{array}$ & / \\
\hline $\begin{array}{l}\text { Features: not } \\
\text { visible enough }\end{array}$ & $\begin{array}{l}\text { Synthesis not found }(\mathrm{N}) \text {; } \\
\text { Drug substitution not found } \\
(\mathrm{Ph}) \text {; Feature to enter data } \\
\text { hard to find }(\mathrm{N}, \mathrm{P})\end{array}$ & $\begin{array}{l}\text { Conversion of home treatment } \\
\text { into hospital order not found } \\
\text { (P); Scheduling and validating } \\
\text { an appointment not found (S) }\end{array}$ & / \\
\hline $\begin{array}{l}\text { Task allocation } \\
\text { issues }\end{array}$ & $\begin{array}{l}\text { Nurses access to ordering } \\
\text { page }(\mathrm{N})\end{array}$ & $\begin{array}{l}\text { Administrative discharge } \\
\text { allocated to nurses (A) }\end{array}$ & / \\
\hline $\begin{array}{l}\text { Errors } \\
\text { management }\end{array}$ & $\begin{array}{l}\text { Error message not } \\
\text { understood }(\mathrm{T}) \text {; Diagnosis } \\
\text { automatically copied from a } \\
\text { previous entry }(\mathrm{P})\end{array}$ & $\begin{array}{l}\text { Error message not understood } \\
(\mathrm{T}) ; \quad \text { Patient's name } \\
\text { concatenated }(\mathrm{A}) ; \text { Buttons too } \\
\text { close to each other }(\mathrm{Ph})\end{array}$ & $\begin{array}{l}\text { Error message not } \\
\text { understood }(\mathrm{T}) \text {; } \\
\text { Drug validation } \\
\text { without password } \\
\text { (P) }\end{array}$ \\
\hline $\begin{array}{l}\text { Inefficient alert } \\
\text { system }\end{array}$ & / & No alert for duplicate orders $(\mathrm{P})$ & $\begin{array}{l}\text { Alert concerning } \\
\text { another patient }(\mathrm{P})\end{array}$ \\
\hline
\end{tabular}

Applying the usability walkthrough method during the competitive usability evaluation of several EHRs to select the short-list that will be in-depth evaluated as 
advised by [11] requires time and resources to prepare the participants to the method, to prepare the scenarios and clinical data. However, once the material is prepared, it can be reused for as many candidates as necessary. Similarly, once the participants have been trained to the method, they can apply it repeatedly. From this point of view, usability walkthrough is not fundamentally more time and resource-consuming than methods used during scenario-based demonstrations (e.g. HED, DPUQ $[12,13]$ ). Besides, the usability walkthrough presents the advantage of allowing end-users to really interact with the technologies and not make an opinion through salesmen's talents. Besides it puts the participants in more realistic conditions than demonstrations by vendors' salesmen [2].

The full results of the comparison of the three EHRs were provided to the hospital's procurement process team to help them make their short-list decision. The next step in the procurement in an in-depth evaluation of the finalist EHRs by a wider diversity of end-users (incl. surgeons, anesthesiologists, various medical specialists).

\section{References}

[1] Tyllinen M, Kaipio J, Lääveri T. A Framework for Usability Evaluation in EHR Procurement. Stud Health Technol Inform. 2018;247:446-50.

[2] Kushniruk A, Beuscart-Zéphir M-C, Grzes A, Borycki E, Watbled L, Kannry J. Increasing the safety of healthcare information systems through improved procurement: toward a framework for selection of safe healthcare systems. Healthc Q. 2010;13 Spec No:53-8.

[3] Linder JA, Schnipper JL, Tsurikova R, Melnikas AJ, Volk LA, Middleton B. Barriers to electronic health record use during patient visits. AMIA Annu Symp Proc. 2006;2006: 499-503.

[4] Gans D, Kralewski J, Hammons T, Dowd B. Medical groups' adoption of electronic health records and information systems. Health Aff (Millwood). 2005;24:1323-33.

[5] Kaipio J, Lääveri T, Hyppönen H, Vainiomäki S, Reponen J, Kushniruk A, et al. Usability problems do not heal by themselves: National survey on physicians' experiences with EHRs in Finland. Int J Med Inform. 2017;97:266-81.

[6] Melnick ER, Dyrbye LN, Sinsky CA, Trockel M, West CP, Nedelec L, et al. The Association Between Perceived Electronic Health Record Usability and Professional Burnout Among US Physicians. Mayo Clin Proc. 2020;95: 476-87.

[7] Koppel R, Metlay JP, Cohen A, Abaluck B, Localio AR, Kimmel SE, Strom BL. Role of Computerized Physician Order Entry Systems in Facilitating Medication Errors. JAMA. 2005;293(10): 1197-203.

[8] Han YY, Carcillo JA, Venkataraman ST, Clark RSB, Watson RS, Nguyen TC, et al. Unexpected increased mortality after implementation of a commercially sold computerized physician order entry system. Pediatrics. 2005;116: 1506-12.

[9] Wawrzyniak C, Marcilly R, Baclet N, Hansske A, Pelayo S. EHR Usage Problems: A Preliminary Study. Stud Health Technol Inform. 2019;257: 484-8.

[10] Ratwani RM, Hettinger AZ, Fairbanks RJ. Barriers to comparing the usability of electronic health records. Journal of the American Medical Informatics Association. 2017;24: e191-3.

[11] Schumacher RM, Webb JM, Johnson KR. How to select an elctronic health record system that healthcare professionals can use. User Centric. 2009.

[12] Tyllinen M, Kaipio J, Lääveri T, Nieminen M. End-Users' Voice in EHR Selection: Development of a Usability Questionnaire for Demonstrations in Procurement (DPUQ). Stud Health Technol Inform. 2017;234: 346-51.

[13] Tyllinen M, Kaipio J, Lääveri T, Nieminen MHT. We Need Numbers!: Heuristic Evaluation during Demonstrations (HED) for Measuring Usability in IT System Procurement. Proceedings of the $2016 \mathrm{CHI}$ Conference on Human Factors in Computing Systems, San Jose California USA: ACM; 2016, 4129-41.

[14] Scapin DL, Bastien JMC. Ergonomic criteria for evaluating the ergonomic quality of interactive systems. Behaviour \& Information Technology. 1997;16: 220-31.

[15] Brooke J. SUS: a "quick and dirty" usability scale. Usability eval ind. 1996;189: 4-7.

[16] Bangor A, Kortum PT, Miller JT. An Empirical Evaluation of the System Usability Scale. International Journal of Human-Computer Interaction. 2008;24: 574-94.

[17] Zahabi M, Kaber DB, Swangnetr M. Usability and Safety in Electronic Medical Records Interface Design: A Review of Recent Literature and Guideline Formulation. Human Factors. 2015;57(5): 805-34. 